\section{Swiss sports and exercise medicine: educate and activate}

\author{
Boris Gojanovic $^{\oplus 1,2}$
}

Welcome to the 2019 Swiss Sports Medicine issue of BJSM. Our past 2 years have been busy with the development of interdisciplinary collaborations and the involvement of undergraduates in sports and exercise medicine (SEM). These have led to the successful \#sportsuisse2018 Hip and Groin conference with our friends from the Swiss Sports Physiotherapy Association, and the continuation of our yearly Student's Day, a preconference event to our Annual Meeting. Sports medicine being the dynamic branch that we cherish, we strive to bring new projects to life, in order to disseminate knowledge and improve the well-being of our Swiss population. Two new domains have kept us busy recently: the reform of our national sports medicine curriculum and the development of the 'exercise' component in Swiss SEM.

\section{A NEW CURRICULUM TO MEET INTERNATIONAL STANDARDS}

Under the leadership of Drs André Leumann and Kerstin Warnke, the Swiss Sports Medicine Society set out to revise our curriculum to bring the best current content to our future graduates. New topics have emerged in the past few years, and doctors' expanded activities in SEM mean this must be reflected in the specialist curriculum.

We are thankful that this task has also been tackled by the International Syllabus in Sport and Exercise Medicine Group (ISSEMG) in an ongoing Delphi process, the basis of which was published in BJSM last year. ${ }^{1}$ Being part of this process helped the Swiss Sports Medicine Society design the new curriculum.

Another key step in our revision was to integrate the best knowledge available to our future SEM doctors, in the form of standardised reference material. One internationally recognised textbook in SEM is now part of our curriculum, as well as a series of consensus statements

\footnotetext{
${ }^{1}$ Swiss Olympic Medical Center, Hopital de la Tour, Meyrin, Geneva, Switzerland

${ }^{2}$ Interdisciplinary Center for Adolescent Sports Medicine, Woman-Mother-Child Department (DFME), CHUV, Lausanne, VD, Switzerland
}

Correspondence to Dr Boris Gojanovic, Swiss Olympic Medical Center, Hopital de la Tour, Meyrin, Geneva, Switzerland; boris.gojanovic@latour.ch

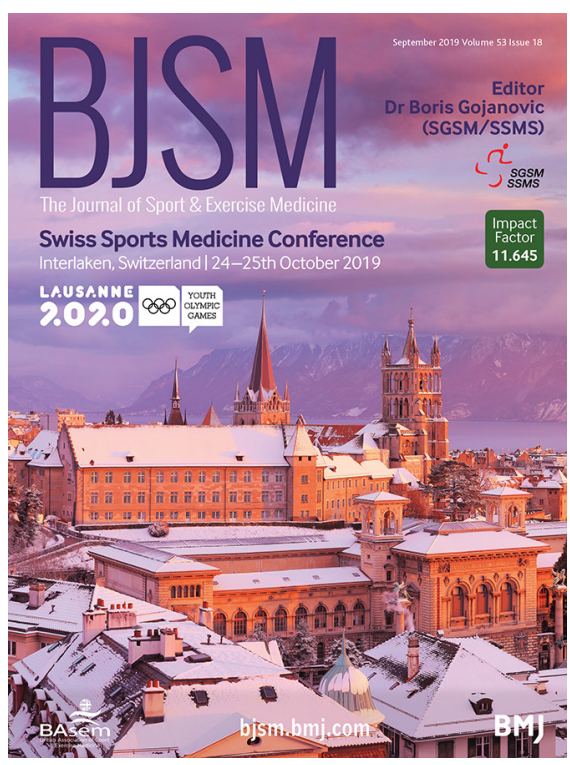

Figure 1 Join us at the Swiss Medicine Society (SGSM/SSMS) Annual Meeting in Interlaken on 24-25 October 2019.

from leading experts, most of them published with the support of the International Olympic Committee.

The new curriculum has now started and we are excited to keep developing the content and delivery for the future of our profession.

\section{PUTTING THE 'EXERCISE' IN SWISS SPORTS (AND EXERCISE?) MEDICINE}

The importance of physical activity and exercise is widely accepted in societal and academic circles, yet there is a gap in leadership at many levels. As active members of the medical community, sports medicine clinicians and leaders must accept responsibility to both serve and lead. The multilevel actions required start in our opinion with the awareness of our members. We have established an exercise medicine commission, which has put together two special 'exercise' issues of our journal, Swiss Sports \& Exercise Medicine. The first one was published in $2018^{2}$ and the second one is due at the end of 2019.

At our Annual Meeting in Interlaken, Switzerland, on 24 and 25 October 2019, we will start with an exercise medicine symposium that will bring together international and national experts. In addition, we are exploring a possible change in the society's name, one which integrates exercise. The multilingual nature of Switzerland is our strength and it comes with a welcome challenge.

\section{IN THIS SWISS SPORTS MEDICINE} ISSUE

Other main topics at our Annual Meeting will be the knee and the travelling athlete. For our issue of BJSM, we have chosen a beautiful mix of papers covering these topics. In the editorial section, we present the importance of every movement-related huff and puff, coined as high-intensity incidental physical activity (see page 1137). Also featured is a strong call against the use of MRI in degenerative meniscal problems, for the self-efficacy and empowerment of patients (see page 1139). In the full articles section, papers explore postACL injury questions: return to sport, (see page 1154) rate of knee osteoarthritis (see page 1162) and patellofemoral osteoarthritis (see page 1168).

International competitions and travel pose challenges with illnesses and a study in athletics championships (see page 1174) reminds us that upper respiratory tract and gastrointestinal infections are the main issues athletes face.

Finally, although we understand the unique multiple benefits of physical activity and exercise, we must recognise that the response to this excellent health stimulus varies and that genetics play an important part (see page 1141). Every step counts, but not to the same extent in everyone.

We thank the BJSM team for fostering growth and fruitful collaboration among the 26 member societies. The Swiss Sports Medicine Society looks forward to our new challenges and opportunities to connect with the international sports and exercise medicine community such as in Monaco at the member society pre-event on 11 March 2020.

Even before that, in January 2020, the world will be right at our doorstep-Switzerland will host the Youth Olympic Games in Lausanne (Figure 1). This is a lot more than a sporting event. It is a learning and sharing opportunity for all involved-athletes, coaches, healthcare and sports professionals, not to forget the media and spectators. We, as sports medicine educators will be part of this event, and we hope to nurture the seeds of a healthy, sustainable participation in sports and exercise for future generations. 


\section{Warm up}

Acknowledgements Thanks to Babette Pluim and Karim Khan for their suggestions which helped improve the text.

Funding The authors have not declared a specific grant for this research from any funding agency in the public, commercial or not-for-profit sectors.

Competing interests None declared.

Patient consent for publication Not required.

Provenance and peer review Commissioned; internally peer reviewed. (c) Author(s) (or their employer(s)) 2019. No commercial re-use. See rights and permissions. Published by BMJ.

$$
\text { D) Check for updates }
$$

To cite Gojanovic B. Br J Sports Med 2019;53:1129-1130.

Accepted 10 June 2019

Br J Sports Med 2019;53:1129-1130. doi:10.1136/bjsports-2019-101139

\section{REFERENCES}

1 Humphries D, Jaques R, Dijkstra HP, et al. A Delphi developed syllabus for the medical specialty of Sport and exercise medicine. Br I Sports Med 2018:52:490-2.

2 Sports S, Medicine E. 66(3), 2018. Available: https:// sgsm.ch/publikationen/swiss-sports-exercisemedicine/archiv/2018/ [Accessed on 31 May 2019]. 